\title{
The Effect of Storage Solutions on Mineral Content of Enamel
}

\author{
Asli Secilmis $^{1 *}$, Erhan Dilber ${ }^{2}$, Nilgun Ozturk ${ }^{3}$, Fatma Gokmen Yilmaz ${ }^{4}$ \\ ${ }^{1}$ Department of Prosthodontics, Faculty of Dentistry, University of Gaziantep, Gaziantep, Turkey; ${ }^{2}$ Department of Prosthodontics, \\ Faculty of Dentistry, Sifa University, İzmir, Turkey; ${ }^{3}$ Department of Prosthodontics, Faculty of Dentistry, University of Selcuk, \\ Konya, Turkey; ${ }^{4}$ Department of Soil Science, Faculty of Agricultural, University of Selcuk, Konya, Turkey. \\ Email: "acarasli@hotmail.com, dilberhan@gmail.com, nilgun25@hotmail.com,f_gokmen1@hotmail.com
}

Received May $12^{\text {th }}, 2013$; revised June $13^{\text {th }}, 2013$; accepted June $25^{\text {th }}, 2013$

Copyright (C) 2013 Asli Secilmis et al. This is an open access article distributed under the Creative Commons Attribution License, which permits unrestricted use, distribution, and reproduction in any medium, provided the original work is properly cited.

\begin{abstract}
Purpose: This study evaluated the influence of different storage times and storage solutions on the mineral content of enamel. Methods: Ninety enamel slabs were randomly divided into 2 groups of 45: a 45-day group and a 90-day group. Each of these main groups was further sub-divided into 9 experimental groups of 5 slabs, and each sub-group was stored in a different storage solution. The mean percentage weights of 5 elements (calcium, potassium, sodium, phosphorus, and magnesium) presented in each enamel slab was measured after storage using inductively coupled plasmaatomic emission spectrometry. Two-way analysis of variance (ANOVA) and Turkey's honestly significant difference tests were used to analyze differences between the groups. Results: Storage conditions significantly affected the levels of calcium, potassium, sodium, and phosphorus $(p<0.05)$. Storage procedures can significantly affect the calcium, potassium, sodium, and phosphorus contents of enamel.
\end{abstract}

Keywords: Storage Solution; Storage Time; Enamel; ICP-AES; Mineral Content

\section{Introduction}

One of the approaches utilized by clinicians when selecting products to use in clinical practice is to compare their performance, both in vitro and in vivo, in published studies. Some in vitro adhesive studies suggest that 2 factors can affect the mineral content of extracted teeth or enamel specimens: the initial sterilization methods that they are subjected to and the conditions under which they are stored [1]. The conditions under which extracted teeth or enamel specimens are stored are not standardized; storage solutions vary widely, as does the duration of storage [2].

More than 15 different storage solutions have been routinely utilized for the storage of extracted teeth or enamel samples. These include glutaraldehyde, ethanol, methanol, formalin, neutral buffered formalin, distilled water (DW), DW with thymol, phosphate-buffered saline (PBS), PBS with thymol, sodium hypochlorite, sodium azide, aqueous chloramine, chloramine- $\mathrm{T}$, physiological saline solution, cetylpyridinium chloride, $\mathrm{H}_{2} \mathrm{O}_{2}$, and artificial saliva [2-16]. Other storage methods incorporate

"Corresponding author. exposure to steam autoclaving, dry heat, gamma radiation, ethylene oxide, and freezing $[1,5,12,15]$. Reported storage times range from a few hours to years, and the frequency at which the solution is changed also varies $[2$, $6,13,17]$.

Dentin contains $70 \mathrm{wt} \%$ mineral content, $20 \mathrm{wt} \%$ organic substances, and $10 \mathrm{wt} \%$ water. Enamel consists almost exclusively of minerals, which account for $95 \mathrm{wt} \%$, most of which is carbonate apatite. The remaining $5 \mathrm{wt} \%$ comprises organic substances $(4 \mathrm{wt} \%)$ and water $(1 \mathrm{wt} \%)$ [18]. Because of these differences in structural composition, the effect that any given storage solution has on enamel may differ from the effect that the same solution has on dentin.

The effects that the composition of the storage solution and the duration of storage exert on bond strength have been the focus of numerous studies that have used dentin as the substrate $[10,17]$. However, only a few studies have investigated adhesion to enamel $[8,14]$. Using bovine enamel, de MeloMaranhão et al. [19] evaluated the influence of 4 of the most commonly used storage solutions (distilled water, artificial saliva, $0.1 \%$ thymol, and saline) on enamel substrate over a long storage period (90 days) 
and monitored morphological surface patterns. They reported that storage solutions may alter the dental enamel substrate and that further studies incorporating longer observation periods are required to elucidate the permeability of enamel [19].

The aim of this study was to evaluate changes in the calcium $[\mathrm{Ca}]$, potassium $[\mathrm{K}]$, sodium $[\mathrm{Na}]$, phosphorus $[\mathrm{P}]$, and magnesium $[\mathrm{Mg}]$ composition of enamel slabs stored in different solutions and for different durations using inductively coupled plasma-atomic emission spectrometry (ICP-AES).

\section{Materials and Methods}

The study protocol described below was reviewed and approved by the relevant ethics committee of the Faculty of Medicine, Gaziantep University, before commencement of the study (protocol number: 05-2009/209).

\subsection{Preparation of Enamel Slabs}

Freshly extracted human upper molar wisdom teeth that were nonerupted were cleaned and then mounted in quadrangular molds in an autopolymerizing acrylic resin (Meliodent; Bayer Dental Ltd., Newbury, UK). Mesiobuccal, distobuccal, and palatinal surfaces of crowns were cut using a diamond saw under water cooling (Isomet; Buehler Ltd., Lake Bluff, IL, Ill, USA), and 3 enamel slabs measuring $2 \times 2 \times 1 \mathrm{~mm}$ were obtained from each tooth. The 90 enamel specimens thus derived were then randomly assigned to 2 groups of 45 specimens. The specimens in 1 group were stored for 45 days, and those in the other group were stored for 90 days (Figure 1). The teeth within each of these 2 groups were further subdivided into 9 storage solution sub-groups of 5 teeth each. The solutions investigated were DW alone (DW), DW with $0.1 \%$ thymol (DW-T), PBS with $0.1 \%$ thymol (PBS-T), saline (S), DW with $10 \%$ formalin (DW-F), PBSwith $10 \%$ formalin (PBS-F), DW with $2 \%$ glutaraldehyde (DW-G), PBS with $2 \%$ glutaraldehyde (PBS-G), and artificial saliva (AS) (Table 1 and Figure 1). Each enamel slab was placed in $2 \mathrm{ml}$ of the assigned storage solution. Specimens were stored in light-proof bottles at room temperature, for either 45 or 90 days. Five teeth constituting the control group were cleaned and stored at $-20^{\circ} \mathrm{C}$, and enamel slabs were prepared from these teeth after 45 days. The composition of artificial saliva was $1.5 \mathrm{mmol} / \mathrm{L} \mathrm{CaCl}_{2}, 8.2$ $\mathrm{mmol} / \mathrm{L} \mathrm{NaHCO}_{3}, 4.8 \mathrm{mmol} / \mathrm{L} \mathrm{NaCl}, 137 \mathrm{mmol} / \mathrm{L} \mathrm{KCl}$, and $4 \mathrm{mmol} / \mathrm{L} \mathrm{KH}_{2} \mathrm{PO}_{4}$.

\subsection{ICP-AES Technique}

The enamel slabs in each group were removed from their respective storage solutions and stored at $65^{\circ} \mathrm{C}$ in a cabinet desiccator (Venticell, Italy) until they reached a pre-determined weight, as measured by an electronic balance (Electronic Balance AX200; Shimadzu Corporation, Japan). Five milliliters of nitric acid $\left(\mathrm{HNO}_{3}\right)$ and $2 \mathrm{ml}$ of hydrogen peroxide $\left(\mathrm{H}_{2} \mathrm{O}_{2}\right)$ were then added to the specimens, and they were heated to $210^{\circ} \mathrm{C}$ in a microwave oven (CEM MarsXpress, USA) until they dissolved. The levels of each of the 5 elements under investigation $(\mathrm{Ca}, \mathrm{K}, \mathrm{Na}$, $\mathrm{P}$, and $\mathrm{Mg}$ ) were then measured in each specimen using

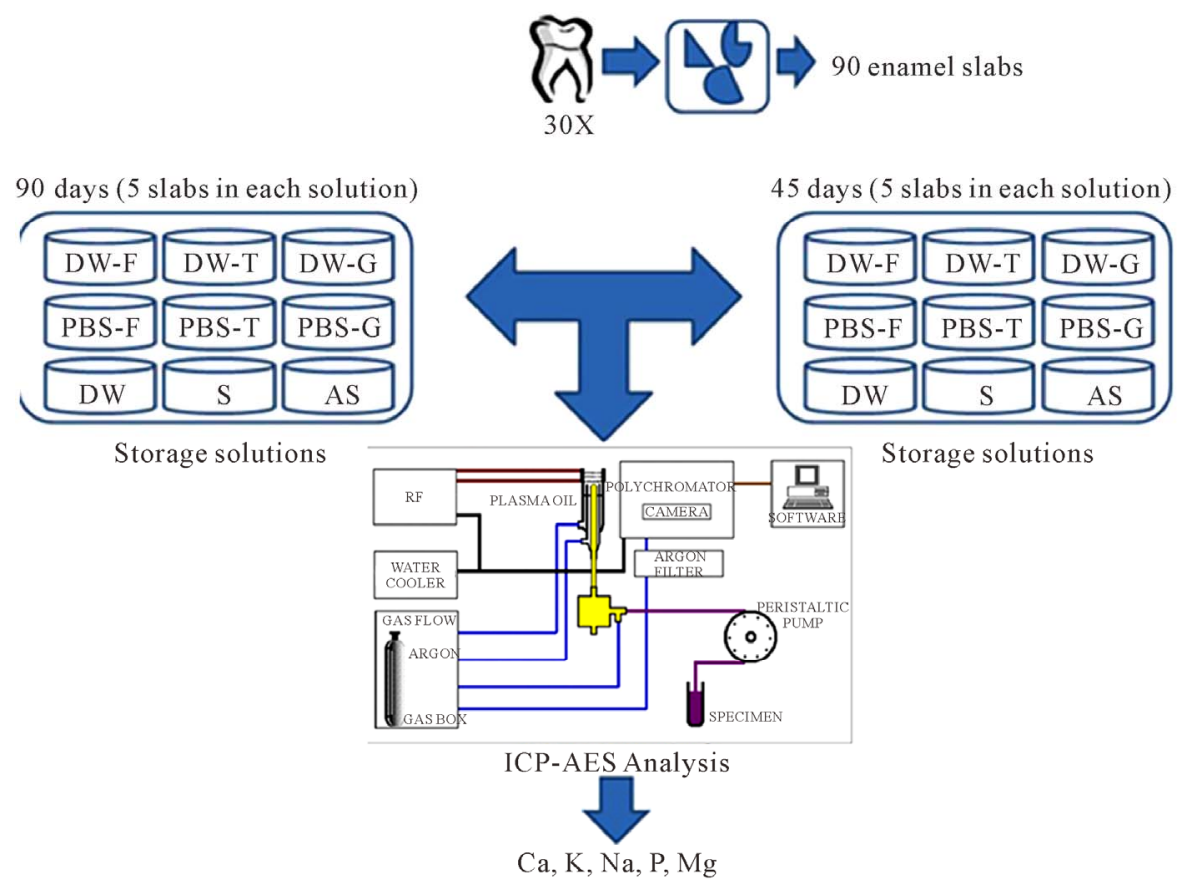

Figure 1. The scheme of preparing and analyzing enamel specimens. 
Table 1. pH measurements and elemental compositions of the storage solutions (ppm).

\begin{tabular}{|c|c|c|c|c|c|c|}
\hline \multirow{2}{*}{ Groups } & \multirow{2}{*}{ pH } & \multicolumn{5}{|c|}{ Elemental Composition } \\
\hline & & Ca & $\mathbf{K}$ & $\mathrm{Na}$ & $\mathbf{P}$ & Mg \\
\hline DW-T & 4.5 & 0.39 & 0.43 & 0.81 & 0.65 & 0.00 \\
\hline PBS-T & 7.4 & 1.12 & 4.57 & 60.04 & 2373.63 & 0.00 \\
\hline $\mathrm{S}$ & 6.2 & 0.53 & 1.39 & 62.25 & 0.00 & 0.00 \\
\hline DW-F & 2.5 & 1.39 & 0.41 & 0.57 & 0.35 & 0.00 \\
\hline PBS-F & 7.4 & 3.61 & 7.62 & 100.90 & 2989.04 & 0.00 \\
\hline DW & 6.3 & 0.90 & 1.01 & 0.58 & 0.18 & 0.00 \\
\hline DW-G & 2.5 & 0.95 & 0.47 & 3.22 & 4.59 & 0.00 \\
\hline PBS-G & 7.4 & 2.58 & 5.97 & 59.78 & 2320.02 & 0.00 \\
\hline AS & 7.4 & 5.08 & 519.56 & 82.02 & 93.05 & 0.00 \\
\hline
\end{tabular}

*The groups are distilled water with $0.1 \%$ thymol (DW-T), phosphate-buffered saline with $0.1 \%$ thymol (PBS-T), saline (S), distilled water with $10 \%$ formalin (DW-F), phosphate-buffered saline with $10 \%$ formalin (PBS-F), distilled water (DW), distilled water with $2 \%$ glutaraldehyde (DW-G), phosphate-buffered saline with $2 \%$ glutaraldehyde (PBS-G) and artificial saliva (AS).

ICP-AES (Vista AX; Varian, Australia). Each element was measured in triplicate for each sample. The comparative content of each mineral contained therein was calculated in terms of percentage by weight.

\subsection{Statistical Analyses}

Differences between the groups were statistically analyzed by 2-way analysis of variance (ANOVA) and Turkey's honestly significant difference (HSD) tests, and $p<$ 0.05 was deemed to indicate statistical significance. The statistics program SPSS (Version 13) was used for all analyses.

\section{Results}

ANOVA indicated that the Ca content of slabs was not affected by storage times $(p=0.384)$, while it was significantly affected by storage solutions $(p<0.05)$. There was no interaction between storage solutions and storage times for $\mathrm{Ca}$ content $(p=0.168)$. The $\mathrm{K}, \mathrm{Na}$, and $\mathrm{P}$ content of enamel was significantly affected by storage solutions and storage times $(p<0.05)$, and there was significant interaction between the 2 factors for $\mathrm{K}, \mathrm{Na}$, and $\mathrm{P}$ content $(p<0.05)$. The Mg content of the slabs was not affected by storage ( $p>0.05$; Table 2$)$.

Mean percentage weights and standard deviations of the 5 elements for each group are summarized in Table 3. The only significant differences in $\mathrm{Ca}$ content were between the control group and the DW-G-45 and AS-45 groups $(p<0.05)$. The only significant differences evident with regard to $\mathrm{K}$ content were between the control group and the AS-45 and AS-90 groups $(p<0.05)$. The K levels of enamel slabs in both AS groups increased sig- nificantly $(p<0.05)$. Storage times had a significant effect on $\mathrm{K}$ levels in the AS groups $(p<0.05)$, which were highest at 45 days. There were significant differences between the groups for Na content $(p<0.05)$. Na levels were significantly increased after storage in the PBSF-45, PBS-T-45, and S-45 groups $(p<0.05)$. Storage times also had a significant effect on $\mathrm{Na}$ levels in the groups stored in buffered solutions (PBS-F and PBS-T), saline solution (S), and artificial saliva (AS) $(p<0.05)$. In these groups, the $\mathrm{Na}$ levels had decreased at 90 days, whereas they were high at 45 days. This was not the case for the AS, DW, DW-G, or DW-T groups. No statistically significant differences in $\mathrm{Mg}$ content were evident between the groups $(p=0.363)$.

\section{Discussion}

Freshly extracted teeth are the most suitable substrate for in vitro evaluation of adhesive systems. However, to acquire a sufficient number of teeth to enable meaningful research, the teeth must be collected over time. This necessitates storage after extraction. Storage solutions are used to prevent dehydration of teeth, as well as crosscontamination between extracted teeth [14].

Studies on the effects of storage solutions, storage methods, and storage times have focused on dentin [2,3,6, $9,10,12,13,17]$. Only a few studies have been published on the effects of storage conditions on enamel $[8,14,19]$. However, the properties of enamel strongly affect the success or failure of restorative materials $[8,11,14,16]$. On the basis of our results, we reject the null hypothesis that storage solution and storage time do not affect the compositional structure of enamel. Thus, the storage process 
Table 2. The results of two way ANOVA.

\begin{tabular}{|c|c|c|c|c|c|c|}
\hline Elements & Source & SS & df & MS & $\mathbf{F}$ & $\mathbf{P}$ \\
\hline \multirow{3}{*}{ Ca } & Storage Solution & 426.391 & 8 & 53.299 & 3.589 & 0.001 \\
\hline & Storage Time & 11.385 & 1 & 11.385 & 0.767 & 0.384 \\
\hline & Storage Solution ${ }^{*}$ Storage Time & 179.868 & 8 & 22.483 & 1.514 & 0.168 \\
\hline \multirow{3}{*}{$\mathbf{K}$} & Storage Solution & 1.771 & 8 & 0.221 & 162.022 & 0.000 \\
\hline & Storage Time & 0.022 & 1 & 0.022 & 16.170 & 0.000 \\
\hline & Storage Solution ${ }^{*}$ Storage Time & 0.053 & 8 & 0.007 & 4.853 & 0.000 \\
\hline \multirow{3}{*}{$\mathrm{Na}$} & Storage Solution & 1.001 & 8 & 0.125 & 21.022 & 0.000 \\
\hline & Storage Time & 0.125 & 1 & 0.125 & 20.945 & 0.000 \\
\hline & Storage Solution* Storage Time & 0.488 & 8 & 0.061 & 10.248 & 0.000 \\
\hline \multirow{3}{*}{$\mathbf{P}$} & Storage Solution & 34.284 & 8 & 4.286 & 3.623 & 0.001 \\
\hline & Storage Time & 26.896 & 1 & 26.896 & 22.736 & 0.000 \\
\hline & Storage Solution ${ }^{*}$ Storage Time & 57.521 & 8 & 7.190 & 6.078 & 0.000 \\
\hline \multirow{3}{*}{ Mg } & Storage Solution & 0.001 & 8 & 0.000 & 0.256 & 0.978 \\
\hline & Storage Time & 0.006 & 1 & 0.006 & 9.029 & 0.004 \\
\hline & Storage Solution ${ }^{*}$ Storage Time & 0.007 & 8 & 0.001 & 1.224 & 0.297 \\
\hline
\end{tabular}

Table 3. Mean percentage weights of the six elements for each group.

\begin{tabular}{|c|c|c|c|c|c|c|}
\hline \multirow[b]{2}{*}{ Groups } & \multicolumn{2}{|c|}{ Ca } & \multicolumn{2}{|c|}{$\mathbf{K}$} & \multicolumn{2}{|c|}{$\mathrm{Na}$} \\
\hline & 45 & 90 & 45 & 90 & 45 & 90 \\
\hline DW-F & $28.24 \pm 4.34^{\mathrm{ab}}$ & $25.45 \pm 1.63^{\mathrm{ab}}$ & $0.09 \pm 0.01^{\mathrm{c}}$ & $0.07 \pm 0.01^{\mathrm{c}}$ & $0.87 \pm 0.03^{\text {ef }}$ & $0.80 \pm 0.03^{\mathrm{de}}$ \\
\hline PBS-F & $27.08 \pm 4.99^{\mathrm{ab}}$ & $24.87 \pm 3.65^{\mathrm{ab}}$ & $0.09 \pm 0.02^{\mathrm{c}}$ & $0.06 \pm 0.01^{\mathrm{c}}$ & $1.12 \pm 0.12^{\mathrm{gh}}$ & $0.90 \pm 0.04^{\mathrm{ef}}$ \\
\hline DW & $30.94 \pm 2.38^{\mathrm{ab}}$ & $29.15 \pm 4.71^{\mathrm{ab}}$ & $0.08 \pm 0.01^{\mathrm{c}}$ & $0.07 \pm 0.00^{\mathrm{c}}$ & $0.81 \pm 0.08^{\text {def }}$ & $0.85 \pm 0.06^{\text {def }}$ \\
\hline DW-T & $27.31 \pm 5.26^{\mathrm{ab}}$ & $28.08 \pm 1.28^{\mathrm{ab}}$ & $0.09 \pm 0.02^{\mathrm{c}}$ & $0.08 \pm 0.01^{\mathrm{c}}$ & $0.84 \pm 0.05^{\mathrm{def}}$ & $0.84 \pm 0.03^{\text {def }}$ \\
\hline PBS-T & $31.12 \pm 3.99^{\mathrm{ab}}$ & $27.10 \pm 3.19^{\mathrm{ab}}$ & $0.08 \pm 0.02^{\mathrm{c}}$ & $0.07 \pm 0.01^{\mathrm{c}}$ & $1.23 \pm 0.11^{\mathrm{j}}$ & $0.93 \pm 0.05^{\mathrm{ef}}$ \\
\hline $\mathrm{S}$ & $32.34 \pm 5.18^{b}$ & $28.80 \pm 1.92^{\mathrm{ab}}$ & $0.09 \pm 0.02^{\mathrm{c}}$ & $0.08 \pm 0.01^{\mathrm{c}}$ & $1.10 \pm 0.10^{\mathrm{gh}}$ & $0.88 \pm 0.02^{\mathrm{ef}}$ \\
\hline DW-G & $22.37 \pm 4.08^{\mathrm{a}}$ & $24.95 \pm 4.01^{\mathrm{ab}}$ & $0.08 \pm 0.01^{\mathrm{c}}$ & $0.06 \pm 0.01^{\mathrm{c}}$ & $0.76 \pm 0.04^{\mathrm{de}}$ & $0.77 \pm 0.03^{\text {de }}$ \\
\hline PBS-G & $26.72 \pm 4.25^{\mathrm{ab}}$ & $26.37 \pm 2.21^{\mathrm{ab}}$ & $0.07 \pm 0.01^{\mathrm{c}}$ & $0.06 \pm 0.01^{\mathrm{c}}$ & $0.98 \pm 0.05^{\mathrm{fg}}$ & $0.88 \pm 0.05^{\mathrm{ef}}$ \\
\hline AS & $22.54 \pm 3.73^{\mathrm{a}}$ & $27.50 \pm 4.92^{\mathrm{ab}}$ & $0.61 \pm 0.10^{\mathrm{d}}$ & $0.44 \pm 0.11^{\mathrm{e}}$ & $0.67 \pm 0.10^{\mathrm{d}}$ & $0.87 \pm 0.19^{\mathrm{ef}}$ \\
\hline \multirow[t]{2}{*}{ Control } & $31.76 \pm 3.95^{\mathrm{b}}$ & & $0.08 \pm 0.01^{\mathrm{c}}$ & & $0.86 \pm 0.04^{\mathrm{ef}}$ & \\
\hline & \multicolumn{2}{|c|}{$\mathbf{P}$} & \multicolumn{2}{|c|}{ Mg } & & \\
\hline Groups & 45 & 90 & 45 & 90 & & \\
\hline DW-F & $17.56 \pm 0.69^{k}$ & $14.93 \pm 0.43^{\operatorname{lmno}}$ & $0.26 \pm 0.02^{\mathrm{p}}$ & $0.22 \pm 0.02^{p}$ & & \\
\hline PBS-F & $17.10 \pm 0.73^{\mathrm{kl}}$ & $14.73 \pm 0.30^{\operatorname{lmno}}$ & $0.25 \pm 0.02^{\mathrm{p}}$ & $0.23 \pm 0.02^{\mathrm{p}}$ & & \\
\hline DW & $16.14 \pm 1.09^{\mathrm{klmn}}$ & $15.39 \pm 0.71^{\mathrm{klmno}}$ & $0.24 \pm 0.05^{\mathrm{p}}$ & $0.23 \pm 0.02^{\mathrm{p}}$ & & \\
\hline DW-T & $17.06 \pm 0.71^{\mathrm{kl}}$ & $15.13 \pm 0.29^{\mathrm{klmno}}$ & $0.26 \pm 0.03^{\mathrm{p}}$ & $0.22 \pm 0.02^{\mathrm{p}}$ & & \\
\hline PBS-T & $16.72 \pm 0.84^{\mathrm{klmn}}$ & $15.01 \pm 0.33^{\mathrm{Imno}}$ & $0.24 \pm 0.02^{\mathrm{p}}$ & $0.23 \pm 0.03^{p}$ & & \\
\hline S & $16.87 \pm 0.72^{\mathrm{klm}}$ & $14.91 \pm 0.22^{1 \mathrm{mno}}$ & $0.24 \pm 0.03^{\mathrm{p}}$ & $0.23 \pm 0.01^{\mathrm{p}}$ & & \\
\hline DW-G & $15.12 \pm 0.68^{\mathrm{klmno}}$ & $14.36 \pm 0.61^{\mathrm{no}}$ & $0.24 \pm 0.02^{\mathrm{p}}$ & $0.22 \pm 0.02^{\mathrm{p}}$ & & \\
\hline PBS-G & $15.20 \pm 0.54^{\mathrm{klmno}}$ & $14.47 \pm 0.32^{\mathrm{mno}}$ & $0.25 \pm 0.01^{\mathrm{p}}$ & $0.23 \pm 0.02^{\mathrm{p}}$ & & \\
\hline AS & $13.01 \pm 2.16^{\circ}$ & $16.01 \pm 3.23^{\mathrm{klmn}}$ & $0.22 \pm 0.04^{\mathrm{p}}$ & $0.24 \pm 0.05^{\mathrm{p}}$ & & \\
\hline Control & $15.39 \pm 0.60^{\mathrm{klmno}}$ & & $0.24 \pm 0.02^{\mathrm{p}}$ & & & \\
\hline
\end{tabular}

*The groups are distilled water with $0.1 \%$ thymol (DW-T), phosphate-buffered saline with $0.1 \%$ thymol (PBS-T), saline (S), distilled water with $10 \%$ formalin (DW-F), phosphate-buffered saline with $10 \%$ formalin (PBS-F), distilled water (DW), distilled water with $2 \%$ glutaraldehyde (DW-G), phosphate-buffered saline with $2 \%$ glutaraldehyde (PBS-G) and artificial saliva (AS). 
may affect the results of in vitro studies.

Ziskind et al. [16] evaluated the effects of $0.1 \%$ cetylpyridinium chloride (CPC), $0.1 \%$ thymol, PBS (positive control), and $3 \% \mathrm{H}_{2} \mathrm{O}_{2}$ (negative control) on microleakage and the bond strength between resin composite and enamel. The authors reported that the $0.1 \%$ CPC, $0.1 \%$ thymol, and PBS groups showed no significant difference in shear bond strength or dye penetration at the occlusal margin, and $0.1 \%$ CPC elicited greater dye penetration at the cervical margin.

Tosun et al. [14] evaluated the effects of 3 storage solutions ( $0.1 \%$ thymol, $10 \%$ formalin, and DW) and 2 storage times ( 24 hours and 2 months) on the microshear bond strength of a resin composite to enamel. They found that storage times did not affect bond strength. Specimens stored in thymol solution showed the lowest bond strength, whereas the DW group had the highest values, but these differences were not statistically significant. The formalin group did not differ significantly from the thymol or DW groups, for either storage period. The authors noted that the chemical nature of the storing agent may affect tooth structure and material properties at the interface tested. They suggested that $10 \%$ formalin may be an appropriate storage solution for studies investigating adhesion to enamel, which is the most highly mineralized tissue in the human body.

The type of storage solution can significantly affect the preservation of microelastic tissue properties. Raum et al. [11] used quantitative time-resolved scanning acoustic microscopy to evaluate dentin and enamel slabs stored in 3 different solutions for 21 days. They reported that neither Hank's balanced salts solution nor artificial saliva altered the elastic properties of enamel. Storage in saline solution resulted in a progressive reduction in the acoustic impedance in enamel, by up to $8 \%$. They found that chemical dissolution of the mineral phase caused a gradual softening at the surfaces of the specimens. The washout occurred gradually and affected only a thin superficial layer.

Jaffer et al. [8] compared dry storage and storage in 6 different solutions (filtered water, $10 \%$ formalin, $1 \%$ chloramine $\mathrm{T}, 10 \%$ chloramine $\mathrm{T}$, isotonic saline solution, and $70 \%$ ethanol) for 7 months at $4{ }^{\circ} \mathrm{C}$. After bonding and rinsing (with oil-free air and water spray or only oil-free air before bonding), the shear bond strength of bonded orthodontic brackets was assessed. They reported that storing the enamel dry or in ethanol had a negative effect on bond strength and that the samples stored in $10 \%$ formalin exhibited statistically significantly higher bond strength. There were no significant differences in bond strength between the other groups in their study. Bovine teeth were used in their study, but notably, Fonseca et al. [20] have reported that human and bovine enamel have similar radio densities. Moreover, bovine enamel may be comparable to human enamel as a substrate for testing bonding [21]. However, human and bovine enamel structures may still differ significantly [8]. Jaffer et al. [8] noted that whether a specimen was rinsed or not rinsed appeared to have little effect on most samples, with the exception of rinsing with formalin. The formalin-rinsed group exhibited the highest bond strength in their study. In our study, the enamel slabs were removed from their storage solutions and dried with oil-free air.

Kitasako et al. [17] noted that changing the storage solution may induce loss of calcium from the dentin. Conversely, in unchanged solutions, equilibrium of calcium ion transfer would be established between the dentin and the storage solutions. They found that there was no statistically significant difference between water and PBS storage solutions with regard to shear bond strength and that the shear bond strength remained significantly higher when unchanged storage solutions were utilized. The solutions were unchanged in our study.

In our study, the Ca content of slabs was not differentially affected by different storage times $(p=0.384)$, while it was significantly differentially affected by different storage solutions $(p<0.05)$. There were no significant differences in $\mathrm{Ca}$ content between the control group and the other groups $(p=0.214)$, with the exceptions of the DW-G-45 and AS-45 groups $(p<0.05)$. Raum et al. [11] have reported that the concentration of calcium ions was too low to balance the absence of phosphate when specimens were stored in sodium chloride. However, in our study, the highest $\mathrm{Ca}$ levels were evident in the specimens stored in saline solution.

The mineral content of enamel was significantly affected by storage solutions and storage times for $\mathrm{K}, \mathrm{Na}$, and $\mathrm{P}(p<0.05)$; K levels of enamel slabs stored in AS, which has a high $\mathrm{K}$ level, increased significantly, and the $\mathrm{K}$ level was highest at 45 days $(p<0.05)$. The Na levels of the specimens in the PBS-F-45, PBS-T-45, and S-45 groups increased significantly $(p<0.05)$. Significant differences were also elicited by different storage times in buffered solutions (PBS-F and PBS-T), saline solution $(\mathrm{S})$, and artificial saliva (AS) $(p<0.05)$. These solutions contain a high quantity of $\mathrm{Na}$, the levels of which tended to be reduced by 90 days but were high at 45 days, with exceptions of the AS group.

There were significant differences in $\mathrm{P}$ content between the groups $(p<0.05)$. Although $\mathrm{P}$ content was unexpectedly low in most groups, PBS and AS solutions elicited high $\mathrm{P}$ levels in the specimens. The P level was highest at 90 days in the AS groups $(p<0.05)$. Storage solutions did not contain $\mathrm{Mg}$, and $\mathrm{Mg}$ levels did not change in any group $(p=0.363)$.

Titley et al. [12] have reported that when teeth are stored by freezing to maintain their freshness, shear bond strength of resin to dentin is the highest. They stated that if 
insufficient numbers of teeth are available at one time, freezing teeth in DW as soon as possible after harvesting is the most optimal method of storage. In fact, water is currently the most popular solution used. This storage solution evidently represents a simple and low-cost means of storing teeth [17].

The difference in elemental content from tooth to tooth and from one region of a tooth to another is a limitation of the current study. The groups were not completely standardized because of this limitation. In conclusion, freshly extracted teeth are the optimal substrate for in vitro tests, as different storage solutions and storage times can result in changes in the mineral content of enamel.

\section{Acknowledgements}

This study was presented in IADR General Session, Barcelona, Spain, 2010 as poster presentation.

\section{REFERENCES}

[1] J. J. Lee, A. Nettey-Marbell, A. Cook, L. A. Pimenta, R. Leonard and A. V. Ritter, "Using Extracted Teeth for Research: The Effect of Storage Medium and Sterilization on Dentin Bond Strengths," The Journal of the American Dental Association, Vol. 138, No. 12, 2007, pp. 15991603.

[2] H. E. Goodis, G. W. Marshall, J. M. White, L. Gee, B. Hornberger and S. J. Marshall, "Storage Effects on Dentin Permeability and Shear Bond Strengths," Dental Materials, Vol. 9, No. 2, 1993, pp. 79-84.

doi:10.1016/0109-5641(93)90079-6

[3] S. R. Armstrong, J. C. Keller and D. B. Boyer, "The Influence of Water Storage and C-Factor on the Dentin-Resin Composite Microtensile Bond Strength and Debond Pathway Utilizing a Filled and Unfilled Adhesive Resin," Dental Materials, Vol. 17, No. 3, 2001, pp. 268-276. doi:10.1016/S0109-5641(00)00081-6

[4] J. De Munck, K. Shirai, Y. Yoshida, S. Inoue, K. Van Landuyt, P. Lambrechts, K. Suzuki, H. Shintani and B. Van Meerbeek, "Effect of Water Storage on the Bonding Effectiveness of 6 Adhesives to Class I Cavity Dentin," Operative Dentistry, Vol. 31, No. 4, 2006, pp. 456-465. doi: $10.2341 / 05-57$

[5] J. P. DeWald, "The Use of Extracted Teeth for in Vitro Bonding Studies: A Review of Infection Control Considerations," Dental Materials, Vol. 13, No. 2, 1997, pp. 7481. doi:10.1016/S0109-5641(97)80015-2

[6] H. E. Goodis, G. W. Marshall and J. M. White, "The Effects of Storage after Extraction of the Teeth on Human Dentine Permeability in Vitro," Archives of Oral Biology, Vol. 36, No. 8, 1991, pp. 561-566. doi:10.1016/0003-9969(91)90105-4

[7] B. Haller, N. Hofmann, B. Klaiber and U. Bloching, "Effect of Storage Media on Microleakage of Five Dentin Bonding Agents," Dental Materials, Vol. 9, No. 3, 1993, pp. 191-197. doi:10.1016/0109-5641(93)90119-B
[8] S. Jaffer, L. J. Oesterle and S. M. Newman, "Storage Media Effect on Bond Strength of Orthodontic Brackets," American Journal of Orthodontics and Dentofacial Orthopedics, Vol. 136, No. 1, 2009, pp. 83-86. doi:10.1016/j.ajodo.2007.07.028

[9] T. Komabayashi, C. Ahn, S. Zhang, Q. Zhu and L. S. Spangberg, "Chronologic Comparison of Root Dentin Moisture in Extracted Human Teeth Stored in Formalin, Sodium Azide, and Distilled Water," Oral Surgery, Oral Medicine, Oral Pathology, Oral Radiology, Vol. 108, No. 1, 2009, pp. e50-e54. doi:10.1016/i.tripleo.2009.03.022

[10] S. Y. Lee and C. T. Lin, "Storage Effect on Dentine Structure and on Resultant Composite Bond Strengths," Journal of Oral Rehabilitation, Vol. 24, No. 11, 1997, pp. 823-834. doi:10.1046/j.1365-2842.1997.00574.x

[11] K. Raum, K. Kempf, H. J. Hein, J. Schubert and P. Maurer, "Preservation of Microelastic Properties of Dentin and Tooth Enamel in Vitro-A Scanning Acoustic Microscopy Study," Dental Materials, Vol. 23, No. 10, 2007, pp. 1221-1228. doi:10.1016/j.dental.2006.11.009

[12] K. C. Titley, R. Chernecky, P. E. Rossouw and G. V. Kulkarni, "The Effect of Various Storage Methods and Media on Shear-Bond Strengths of Dental Composite Resin to Bovine Dentine," Archives of Oral Biology, Vol. 43, No. 4, 1998, pp. 305-311. doi:10.1016/S0003-9969(97)00112-X

[13] M. Toledano, R. Osorio, E. Osorio, F. S. Aguilera, M. Yamauti, D. H. Pashley and F. Tay, "Durability of ResinDentin Bonds: Effects of Direct/Indirect Exposure and Storage Media," Dental Materials, Vol. 23, No. 7, 2007, pp. 885-892. doi:10.1016/j.dental.2006.06.030

[14] G. Tosun, Y. Sener and A. Sengun, "Effect of Storage Duration/Solution on Microshear Bond Strength of Composite to Enamel,” Dental Materials, Vol. 26, No. 1, 2007, pp. 116-121. doi:10.4012/dmj.26.116

[15] J. M. White, H. E. Goodis, S. J. Marshall and G. W. Marshall, "Sterilization of Teeth by Gamma Radiation," Journal of Dental Research, Vol. 73, No. 9, 1994, pp. 15601567.

[16] D. Ziskind, J. Gleitman, I. Rotstein and M. Friedman, "Evaluation of Cetylpyridinium Chloride for Infection Control in Storage Solution," Journal of Oral Rehabilitation, Vol. 30, No. 5, 2003, pp. 477-481. doi:10.1046/j.1365-2842.2003.01091.x

[17] Y. Kitasako, M. F. Burrow, T. Nikaido and J. Tagami, "The Influence of Storage Solution on Dentin Bond Durability of Resin Cement," Dental Materials, Vol. 16, No. 1, 2000, pp. 1-6. doi:10.1016/S0109-5641(99)00061-5

[18] S. Habelitz, G. W. Marshall, M. Balooch and S. J. Marshall, "Nanoindentation and Storage of Teeth," Journal of Biomechanics, Vol. 35, No. 7, 2002, pp. 995-998. doi:10.1016/S0021-9290(02)00039-8

[19] K. de Melo Maranhão, E. B. Klautau, P. M. M. Pereira, R. B. Guimarães and V. G. Pantoja, "The Effect of Storage Solutions on Enamel of Bovine Teeth," Salusvita, Bauru, Vol. 28, No. 2, 2009, pp. 129-134.

[20] R. B. Fonseca, F. Haiter-Neto, H. L. Carlo, C. J. Soares, M. A. Sinhoreti, R. M. Puppin-Rontani and L. Correr- 
Sobrinho, "Radiodensity and Hardness of Enamel and Dentin of Human and Bovine Teeth, Varying Bovine Teeth Age," Archives of Oral Biology, Vol. 53, No. 11, 2008, pp. 1023-1029.

doi:10.1016/j.archoralbio.2008.06.012
[21] L. J. Oesterle, W. C. Shellhart and G. K. Belanger, "The Use of Bovine Enamel in Bonding Studies," American Journal of Orthodontics and Dentofacial Orthopedics, Vol. 114, No. 5, 1998, pp. 514-519. doi:10.1016/S0889-5406(98)70171-4 